\title{
Forest Hydrology, Soil Conservation and Green Barriers in Canary Islands
}

\author{
Juan Carlos SANTAMARTA-CEREZAL",Juan GUZMÁN², \\ Jonay NERIS ${ }^{3}$,Maria P. ARRAIZA ${ }^{4}$,Florin IORAS 5 \\ ${ }^{1}$ Universidad de La Laguna, Technical Superior School of Civil and Industrial Engineering, Spain; jcsanta@ull.es (*corresponding author) \\ ${ }^{2}$ Forestry Consultant, Canary Islands, Spain \\ ${ }^{3}$ Universidad de La Laguna, Department of Soil Science and Geology, Spain; jneris@ull.edu.es \\ ${ }^{4}$ ETSI Montes, Universidad Politécnica de Madrid, Spain; paz.arraiza@upm.es \\ ${ }^{5}$ Buckinghamshire New University, High Wycombe,UK; Florin.Ioras@bucks.ac.uk
}

\begin{abstract}
In volcanic islands, the rainfall regime and its torrential nature, together with the steep slopes and the soil types present are considered to be some of the main factors affecting forest hydrology and soil conservation. In such environments, rain regime is generally irregular and characterized by short and intense rainfalls, which could cause destructive flows at times, followed by long periods of rain absence. The volcanic nature of these islands have as a direct resultant steep slopes which influences the runoff volume and speed, as well as the amount of topsoil susceptible to be detached and transported downstream. The soil type also affects the susceptibility to erosion processes. Andisols are the most typical soil on volcanic islands. Their particularities derive their mineral constituents, called short-range-order products, which provide these soils with an increased structural stability, which in turn reduces their susceptibility to erosion. However, the land use changes and the environmental factors such as rain regime and steep slopes may be determinant factor in destabilizing these soils and ultimately a cause for soil erosion and runoffs, which become a threat to the population downstream. Green barriers have been traditionally used to prevent or reduce these processes, also to enhance the dew effect and the fog water collection, and as a firebreak which acts as a barrier to slow or stop the progress of a wildfire. Wooded species present and subsequently their performance have a major influence on their effectiveness. The use of this natural erosion and fire control methods on volcanic islands is discussed in this paper.
\end{abstract}

Keywords: Canary Islands, erosion control, forest hydrology, green barriers

\section{Forest hidrology and soil conservation}

Two main factors influence the forest hydrology and the soil conservation in volcanic islands, the rain regime and the morphology and topography of these environments. The torrential regime of the rain is typical for some volcanic regions. This characteristic leads to an irregular behaviour of the ravines' flow, with dry stages followed by high flow stages corresponding to rainstorms. Under these conditions, present for example in Canary Islands, it is common the occurrence of torrential events, which involve noticeably erosion processes.

The geological nature and formation of these areas is the second key factor affecting the forest hydrology and the erosion processes in volcanic islands. As a result, the steep slope hillsides are typical of these areas. In these conditions, infiltration is reduced and runoff after a rainstorm transports most of the detached material from the hillsides to the ravines, resulting in the formation of rills and gullies. These slope conditions also lead the runoff speed and its detachment and transport capacity.
When ravines' flows are not properly redirected and evacuated, water and mostly the transported materials represent a danger for distant settlements or incorrectly built or maintained infrastructures.

Erosion is a natural physical-chemical process which detach, transport and deposit soil and rock materials from the earth surface. Human actions could promote but also modify and correct the effect of this process.

Most erosion processes are result of the action of natural factors such as temperature changes, gas effects, water and wind flow, gravity or animal and vegetation actions. Water and wind are the main factors controlling erosion in volcanic islands.

Erosion depends on:

- Rainfall volume and intensity;

- Slope and topography of the area;

- Vegetation cover characteristics;

- Soil physical and chemical properties.

Rainstorms are the driving force of water erosion processes. Rain drops impact the soil surface and detach soil particles. If rain intensity is larger than infiltration capacity, runoff processes starts in a laminar regime, transport- 
10

ing these detached material. This initial flow could be transformed in rill and gully erosion if the runoff volumes and speed, soil characteristics and topography conditions are appropriate. This kind of erosion processes are difficult and expensive to correct.

The occurrence of gully erosion is intimately associated to the soil nature, but also to inappropriate practices and land use. This kind of erosion is the most severe type of erosion,

Globally, erosion processes are considered nowadays as one of the main environmental problem related to the loss of forest cover. This process could be divided into different stages. It starts with the detachment of soil particles by the raindrop impact or the runoff flow forces, continues with the transport of these material by some natural agent (water, wind, etc.) and ends with the deposition of the soil. In volcanic islands, the last process usually takes place at the final stretch of the ravine, close to the coast. Deposits with more than $100 \mathrm{~m}$ depth have been described in ravines from La Gomera (Canary Islands) (Fig. 1).

In Canary Islands, around 329.000 ha ( $43 \%$ of the soil surface) are affected by severe erosion processes due to the wind and water action. In this region, soil losses range from 10 to 50 soil tons per year, with the maximum recorded rate of 200 tons per year (Boli et al., 1991). Fuerteventura and Gran Canaria are the main affected islands with dramatic erosive effects in some parts.

Intense rainstorms in the ravine header lead major erosion processes. The main factors affecting floods and mudflows are related to the rainfall and catchment characteristics, water erosion and channel dynamic.

\section{Green barriers establishment}

Green barriers are natural barriers used in town planning both for aesthetics and noise insulation porpoises. These tree barriers conceal any visual impact related for example to mining or aggregate extraction, but also they act as noise barrier for such activities depending on plant species used and performance.

Green barriers developed in Gran Canaria (Canary Islands, Spain) have become a major environmental defence measure due to their ecological, hydrological, socioeconomic importance and their forest protection action. Similar actions focused on the restoration of the "gallery forest" from La Gomera (Canary Islands, Spain) have been also carried out.

In general, green barriers are developed along the beds of ravines present in the island. Regarding to the potential vegetation for these areas, mono specific formations such as palmeral-Phoenix canariensis Chabaud, sauced-Salix canariensis C. Sm., tarajalera-Tamarix canariensis Willd prevail. "Gallery vegetation" is a typical Monteverde formations composed of evergreen trees and shrubs such as Til (Ocotea foetens (Aiton) Baill), Viñátigo (Persea indica (L.) Spreng) or Barbusano (Apollonias barbujana Nees). These ecosystems show a high plant and animal biodiversity and incorporate a positive visual effect on the scenery (Fig. 2).

The green barriers developed in Gran Canaria are intended to replace the vegetation present in the bed of the ravines. These formations are usually far from the potential vegetation and include non indigenous, invasive or fire-prone species, which pose a significant threat to the safety of the population.

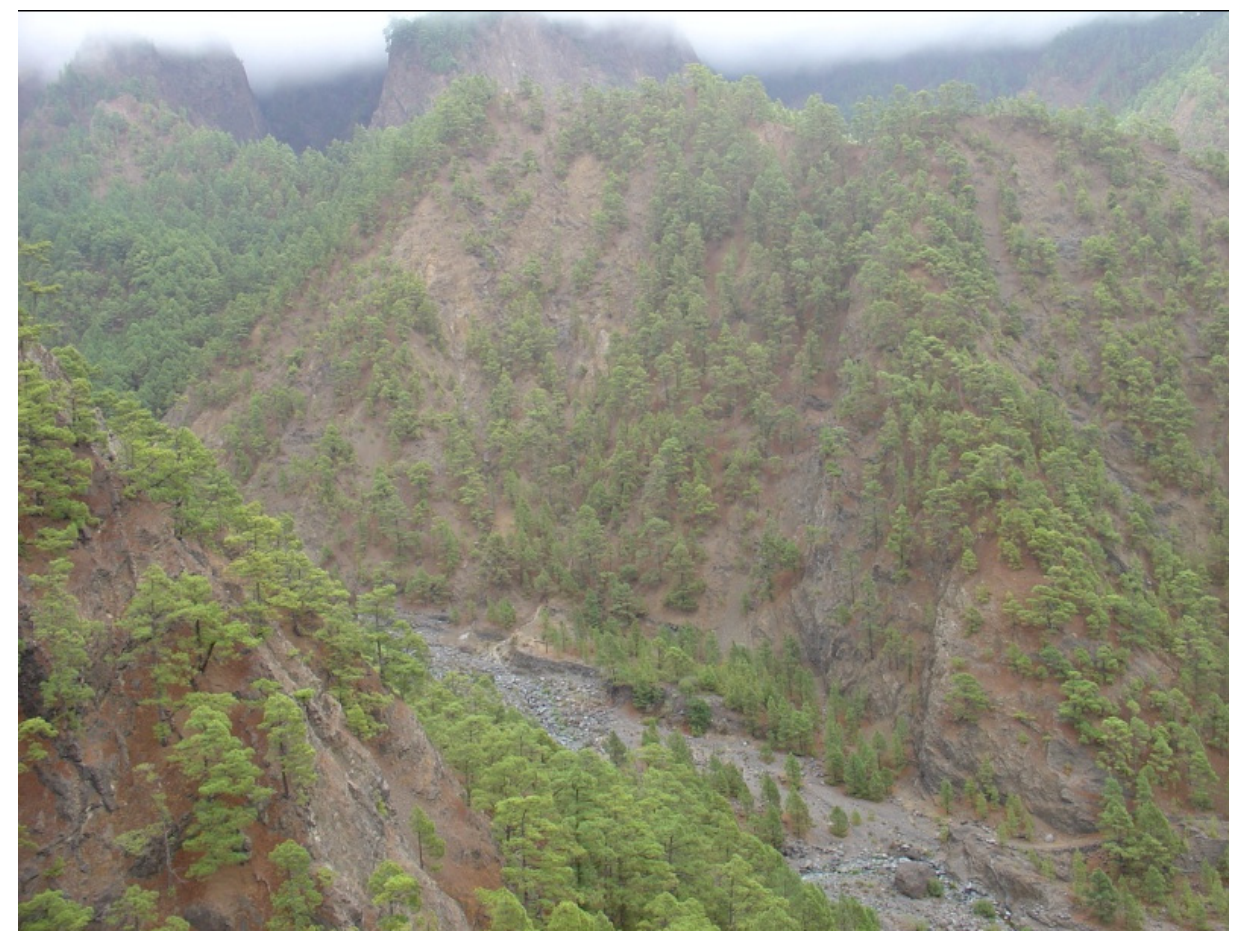

Fig. 1. Las Angustias ravine in La Palma (Canary Islands) 


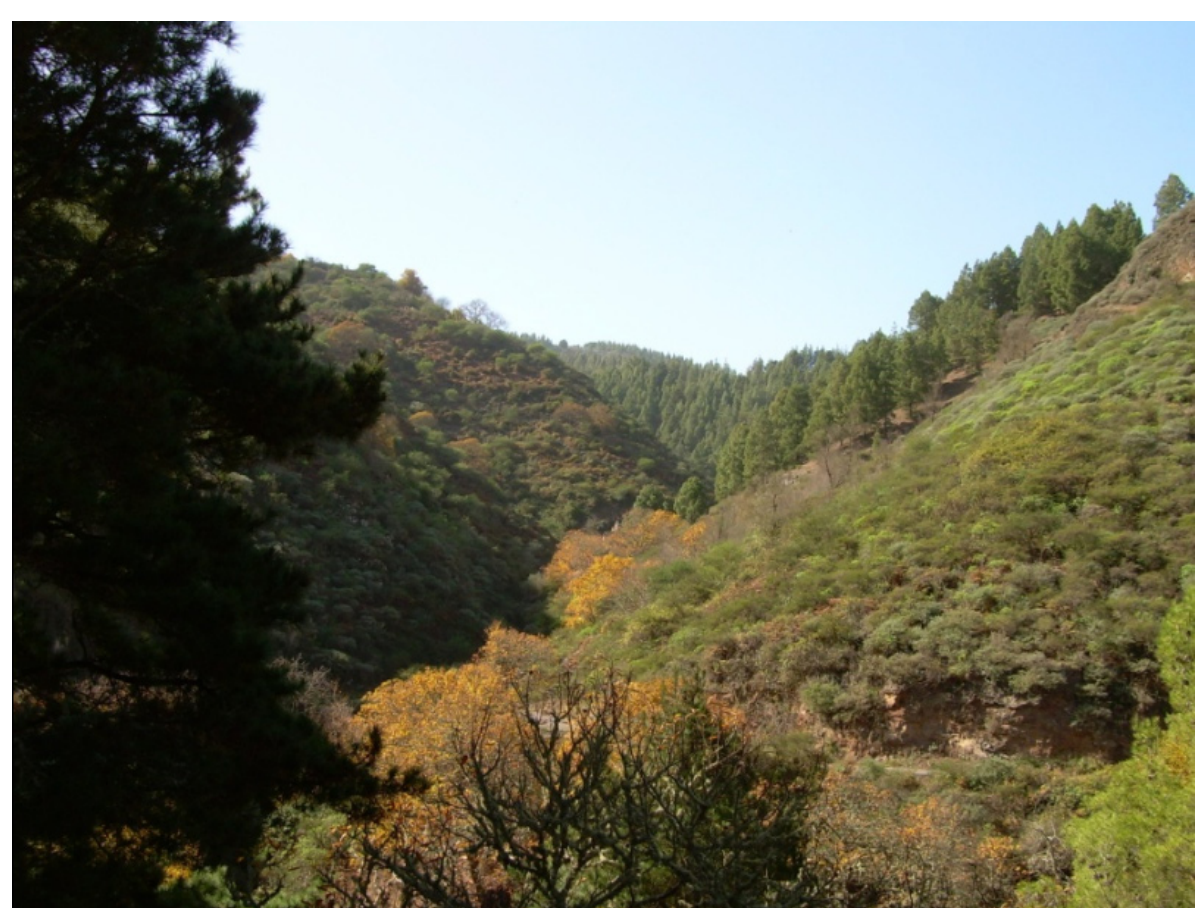

Fig. 2. Green barriers along a ravine's bed (Gran Canaria)

The main objectives of the green barriers are:

\section{- Erosion reduction and flood prevention}

In Canary Islands, erosive processes are developed mainly along the ravines, due to the steep slopes present and related to rainstorms. In this situation, the absence of vegetation cover leads major soil losses, which could be mitigated by the development of green barriers. These structures protect the soil by reducing the raindrop impact and the runoff speed, diminishing the erosion on the bed of the ravine.

- Dew effect and condensation rainfall increase

Although the importance of the "fog or horizontal rainfall" is well established in Canary Islands, the dew effect has been less studied. The dew effect is a physicalmeteorological phenomenon that involves the condensation of the air humidity due to a sharp diminution of the air temperature or to the contact with colder surfaces. In general, this condensation process takes place on the vegetation cover (leaves, branches and steams) or on the soil surface. Despite its importance as water supply mainly in ravines and forested hillsides exposed to the trade wind, the dew effect is partially unknown in Canary Islands (Santamarta Cerezal, 2012a).

\section{- Forest fireprevention}

Green barriers are mainly composed by tree species with low combustion index, which prevent or reduce the fire advance through the ravine's bed and acting as firebreaks.

\section{- Ecological filters}

Green barriers act as filters between the streams and the surrounding environment by preventing or reducing the incorporation of agrochemicals or organic compounds.
Besides, green barriers acts as ecological and socioeconomic factors due to their high biodiversity and their function as supply of forest products to the surrounding communities.

The tree species characteristics will depend on the ecological and socio-economical conditions of the study area. In general, wood species will predominantly be represented by shrubs.

The ravine could be divided into different types, depending to the surrounding area and its influence as follows:

- of Agroforestry influence;

- of Silvopastoral influence;

- of Wet rainforest influence;

- of "Gallery forest" influence;

- of Dry rainforest influence;

- of Thermophile forest influence.

Fire-prone species such as pine (Pinus canariensis $\mathrm{C}$. Sm.) or heath (Erica arborea L.) should be dismissed due to their high capacity of ignition. The species selection will take into account that in ravines, the potential vegetation transitions are usually more extensive.

The ecological and environmental homogeneity of the ravines provide excellent conditions for the development of re-vegetation actions. However, the invasive species could become problematic and affect negatively the reforestation success. Bearing in mind this question, the design of the action including the species selection should take into account the competition degree, especially where the Spanish cane (Arundo donax L.) is present, but also the intensity and temporality of the maintenance activities on the plantation. Therefore, a well-developed forest planning is needed (Santamarta Cerezal, 2012b). 


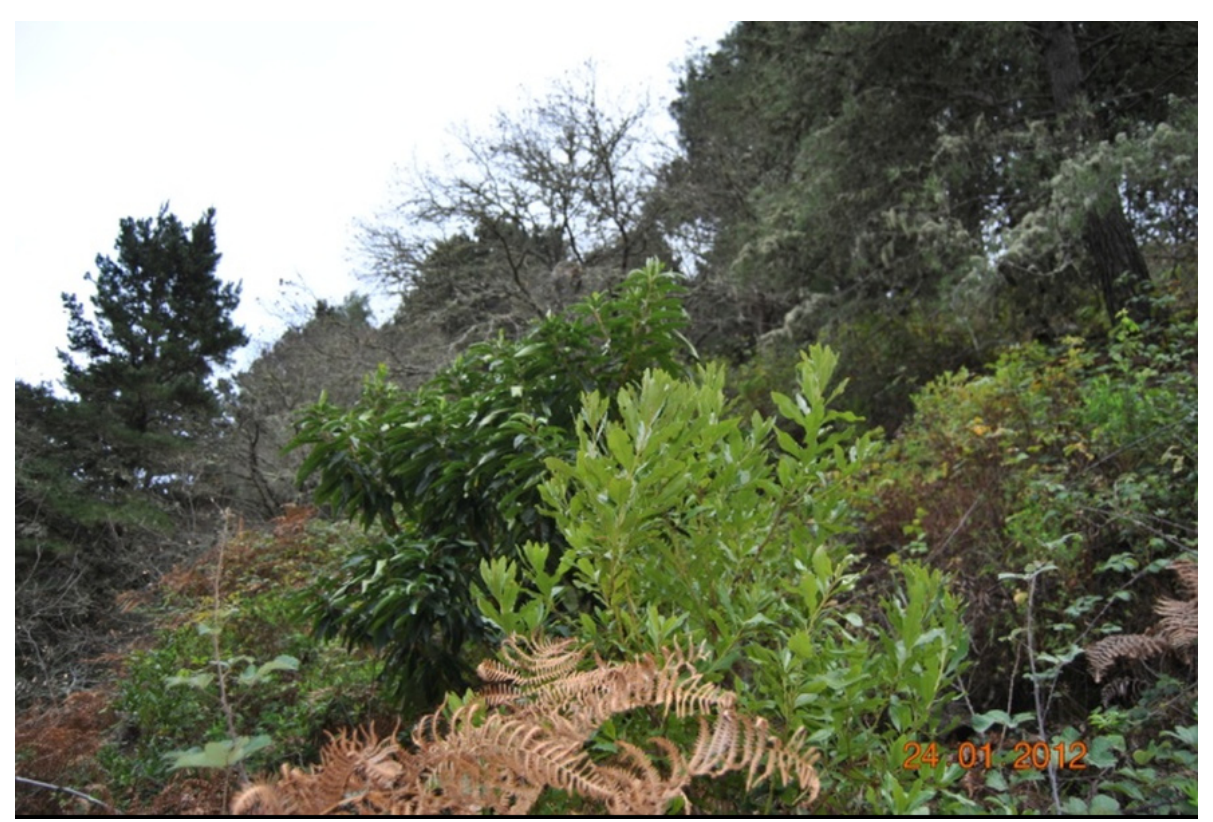

Fig. 3. Canarian madroño (Arbutus canariensis Veillard) and waxmyrtle (Myrica faya Ait) over invasive vegetation in a hillside

In rainforest areas, the Canarian madroño (Arbutus canariensis Veillard) and the wax-myrtle (Myrica faya Ait.) have shown excellent results (Fig. 3) in competition with the elm-leaf blackberry (Rubus ulmifolius Schott) and braken (Pteridium aquilinum (L.) Kuhn) (Guzman, 2004).

In wet environments, the presence of field elm (Ulmus minor Mill.) is welcome because it reduces the invasion of foreign vegetation and acts as a vector of rainforest.

In lowlands where the Spanish cane (Arundo donax L.) is the dominant species, once it has been harvested, mulch derived from cane has been placed over the soil surface. Due to the regeneration capacity of the Spanish cane, successive clearance actions have been done usually using chemical clearing products with good results. However, these actions have generated some social controversy.

In mid and lowlands location, wild olive (Olea cerasiformis Webb \& Berthel) is the most common species used in green barriers (Fig. 4), together with some shrubs such as Orobal (Whitania aristata Pauqui) and Guaydil (Convolvulus floridus L.F.). The experience with azonal species such as Tarajal (Tamarix canariensis Willd.) or Sao (Salix canariensis $\mathrm{C}$. Sm.) shows that it is vital to use seedlings to increase their rooting potential (Guzman, 2008).

In those areas where the transformation of the vegetation is more complicated, mechanical or chemical clear-

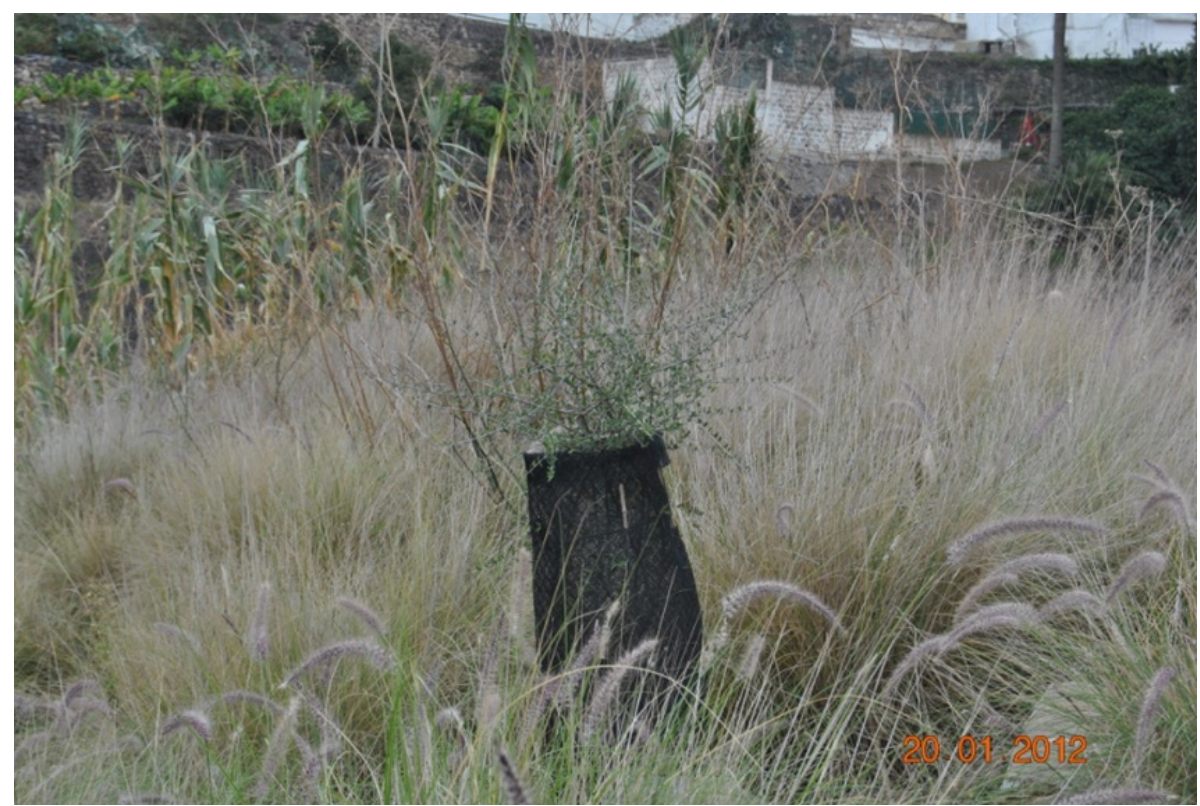

Fig. 4. Survival and development of wild olive (Olea cerasiformis) planted with various saps 
ing of the invasive vegetation and increasing the planting density and the size or age of the plant are recommended. Good results have been obtained in these areas using wild olive (Olea cerasiformis Webb \& Berthel) and Persian turpentine tree (Pistacia atlantica Desf.) with 4 year old saplings.

In Gran Canaria, the development of the green barriers to improve the ecological and economical quality started in 2004, mainly in ravines of forested areas. After the forest fire which broke out in 2007, the prevention actions including the maintenance of the ravine's bed was extended to reduce the fuel material presence. However, the revegetation actions in the ravines were not completed.

The ravine morphology and geometry, the current vegetation and the access and maintenance conditions should be taken into account to develop a green barrier. In general, it is necessary to carry out clearance actions for the elm-leaf blackberry (Rubus ulmifolius Schott) and Spanish cane (Arundo donax L.) green barriers types, which is some cases include removal of solid waste (even abandoned cars).

According to the guidelines developed by local government, the green barriers will be established only at the beginning and the end of the ravine's bed, but not in the central part. The plant distribution will be in a quincunx frame with 2-3 meters between the trees.

\section{Conclusions}

Green barriers have been traditionally used to prevent or reduce these processes, also to enhance the dew effect and the fog water collection, and as a firebreak which acts as a barrier to slow or stop the progress of a wildfire. Wooded species present and subsequently their performance have a major influence on their effectiveness. The tree species characteristics will depend on the ecological and socio-economical conditions of the study area. In general, wood species will predominantly consist of shrubs. The selection of the main species, the preparation actions needed and subsequent maintenance after the plantation will also depend on the environment characteristics and socioeconomic factors.

\section{References}

Boli Z, Bep A, Roose E (1991). Enquête sur l'érosion en région cotonnière du Nord Cameroun. Bull Réseau Erosion 11:127- 138 .

Guzman J (2004). Informe técnico relativo a los proyectos de creación de barreras verdes en barrancos (Green barriers development projects technical report). Gran Canaria. Spain. Servicio Técnico de Medio Ambiente. Cabildo de Gran Canaria.

Guzman J (2008). Creación y mantenimiento de barreras verdes: Experiencia y proyección (Creation and maintenance of green barriers: experience and projection). Proceedings of Conference XV Jornadas Forestales de Gran Canaria. Spain.

Santamarta Cerezal JC (Ed.) (2012a). Forest and environmental engineering in island environments: Methods and experiences in Canary Islands. Universidad de La Laguna. Spain. Inédito.

Santamarta Cerezal JC (Ed.) (2012b). Hydrology and water resources in volcanic areas. Universidad de La Laguna. Spain. Inédito. 